\title{
Vulnerable Groups Of Displaced Populations
}

\author{
M Kett
}

\section{Introduction}

Healthcare professionals are increasingly choosing to deploy on humanitarian missions across the world. These may be short-term placements, for example as part of an emergency disaster-relief operation, or for significantly longer periods as part of a medical team working for any one of the numerous non governmental (NGO) or international organisations (IO) around the world. Alongside preparing for the range of trauma, illness and diseases they may be confronted with, it is also important to be aware of the socio-political contexts of the situations they are being deployed to. Healthcare professionals may encounter people who for a myriad of reasons have left their homes either as refugees or internally displaced people (IDPs). Therefore they need to be aware of the often-challenging contexts of these situations in order to more fully engage with the people concerned. It is important to note that though there are many similarities to the problems and patterns of displacement, there are also certain distinctive features.

The aim of this article is to outline some of the predisposing factors to displacement, some of the immediate and longer-term impacts of displacement, and to contextualise many of the particular considerations that need to be taken into account when working with people or groups who have undergone such experiences. It will highlight how and why IDPs are vulnerable, and what effects this vulnerability can have on conflict recovery. It is hoped that this article will demonstrate some of the wider consequences of conflict and trauma, as well as the broad scope of conflict medicine.

Key Words Displacement, human security, vulnerability, conflict.

\section{Some Causes and Effects of Displacement}

This is obviously a vast and complicated subject, dependent on context, time, and circumstances (1). There are many causes of displacement, which range from manmade (e.g. revolutions, conflict, economic necessity), to natural (e.g. floods, earthquakes), and even state-sponsored development projects (e.g. hydroelectric dams). Whatever the cause, the effects are always numerous and far-reaching. They include the destruction of homes and environment, religious or political persecution, social upheaval, injury, trauma, violence, loss of livelihood, disrupted education and death.

There are a number of systemic warning indicators for potential forced migration; these include historical antecedents (both domestic and international), degree of democracy, economic equality, and geographic location (particularly border areas for geo-political reasons). However, as Schmeidl (2) points out, early warning systems are increasingly geared to assisting the swift repatriation of the displaced in order to divert potential humanitarian crisis. This in effect means people are being returned to less than favourable conditions and circumstances in order to prevent 'flooding' from refugees and migrants. Moreover, there is no guarantee such information will be used for humanitarian purposes.

In terms of forced migration, IDPs are particularly vulnerable to due to the lack of international protection. Efforts are underway to alter this, and include the UN Guiding Principles on Internal Displacement (3). Those who cross international borders are legally recognised by international law as refugees - and can thus claim asylum - while those who remain within the borders of their own country are not. The Global IDP Project estimates there are some 25 million people displaced in 52 countries across the world today. Displacement very often occurs in developing countries with weak economies and limited infrastructure developments. Many of these IDPs face challenges of hunger, inadequate shelter, poverty, psychological stress, natural disasters, and epidemics - particularly HIV/AIDS. Examples include some three million IDPs in the Democratic Republic of Congo (DRC), over 750000 people in the western Darfur region of Sudan (based on February 2004 estimates), nearly three million in Colombia, and over a million in Uganda, Iraq and Burma. These numbers are constantly shifting, and reflect only those who have remained inside the borders, and are thus 'protected' by their own governments.

While refugees may be housed in transit centres as their asylum claims are processed, IDPs do not undergo such a formal process. Therefore, where the often-enormous numbers of vulnerable people end up may be somewhat self-determined, but the United 
Nations High Commissioner for Refugees (UNHCR) usually takes the role of lead agency in the care and protection of refugees and to a lesser extent IDPs. The responsibility for IDPs continues to remain with the government of the country concerned, with all the attendant problems that can imply - as in many cases, the government themselves deliberately targets the displaced, or put another way, contributes to the causes of displacement.

An example of this is the current humanitarian crisis in the Darfur region of western Sudan, where people have been victims of attacks by government-sponsored militia sent to seek out and destroy rebel groups. Many other countries have weak or ineffectual policies toward their IDPs. Moreover, the collapse of state structures, such as in Liberia, Somalia, and potentially Iraq (4), means there is no effective means of support or protection for the displaced. However, even in Colombia, a country with what the Global IDP Project call the "the world's most developed IDP legislation", the abysmal protection situation faced by IDPs demonstrates how this protection can fail. Africa is the most IDP affected continent in the world, with some 13 million mostly conflict related IDPs. But even when ceasefires and peace agreements are made, they do not necessarily lead to the return of the displaced. On the contrary, the return process may cause further problems and render people even more vulnerable.

Overall, there has been a shift by the international communities concerned to prevent widespread displacement in the first place. This has been especially noticeable in joint military-humanitarian interventions acting according to UN mandates has meant that in a number of recent situations, UN peacekeeping forces have been subject to criticisms for (albeit unwittingly) becoming bystanders to events. This makes IDPs even more vulnerable (5). Once displacement occurs, the emphasis is on return rather than seeking alternative solutions to displacement. In part this is driven by the tendency to see large-scale population movements as a threat to international security, as well as in the light of the perceived implications in the post-9/11 world that these events have on asylum and policy decisions. But this also raises the question to what extent refugees and IDPs have security themselves (6).

\section{The Experience of Displacement}

Both before, during and after flight, IDPs and refugees may have experienced conflict, trauma and violence, suffered persecution, hunger, exhaustion, separation from their families and undergone many other painful experiences. Ager (7) has called this whole process the "refugee experience", though it is common to both IDPs and refugees. $\mathrm{He}$ identifies a number of key phases: pre-flight (the phase that may be indicated by early warning systems), such as economic hardship and social disruption, violence and political oppression; flight; reception, and finally, settlement. Settlement decisions usually result from one of three options: repatriations, resettlement or return. All three of these options can be problematic and fraught with difficulties, which will be illustrated below, but include cultural and intergenerational conflicts, difficulties with employment and education, and what has been identified as a danger of reinforcing a discourse of refugee vulnerability (7). Moreover, these processes may take many months or years to complete and should not be seen as linear or sequential.

Derek Summerfield (8) has highlighted the overall shift in emphasis over the past two decades in both research and service provision for refugees from that of material support and rapid integration into the labour market, to a more marked focus on psychological needs and a decrease in emphasis on material needs. This in turn has led to a loss of meaningful roles for refugees, and increasingly they have come to be portrayed as "pathologized" and "helpless" victims, reliant on the support of medical workers to solve their problems in the absence of any other structures. Furthermore, refugees are often treated as second class citizens and are expected to be 'grateful' for whatever they are given (10). Refugees and IDPs are rarely given much voice - especially women - and are often portrayed as one homogenous mass of people with similar problems and issues and with little or no volition of their own. They are depicted as being at the mercy of governments, the international community, and in some cases, members of their own communities.

There are now a number of specialist services set up in host countries to assist refugees and asylum seekers in settling in and recovering from these traumatic experiences. Prominent among these are services provided by psychiatric and psychology departments and charitable organisations. The debate surrounding asylum is a topical one, and the healthcare treatment of refugees and asylum seekers is currently receiving some discussion within the UK. However, the purpose of this article is to contextualise some of these issues within both the global and local setting in order to facilitate a deeper understanding of the whole refugee and IDP process.

\section{Human Security and Vulnerability}

All of the possible outcomes for IDPs and refugees result in an enormous sense of uncertainty and insecurity. Some refugees and IDPs are particularly vulnerable women, children, the elderly, the disabled, the sick, and minority groups. However, 
though vulnerable, they should not be treated as victims. Ascertaining their particular problems and adjusting programmes and assistance can promote independence and self-reliance, focus on social and cultural needs and community structures as well as the essentials.

In the immediate phase of displacement there are, of course, a number of these essential areas. These areas of priority in the care and protection of refugees and IDPs in the emergency phase have been summed up concisely by Médecins Sans Frontiers (Table 1).

\section{Table 1. MSF Top Ten Priorities.}

1. Initial assessment
2. Measles immunisation
3. Water and sanitation
4. Food and nutrition
5. Shelter and site planning
6. Healthcare in the emergency phase
7. Control of communicable diseases and
8. Puidemics
9. Human resources and training
10. Co-ordination
Source: MSF 1997

Displacement is often a protracted affair, and donor funding and agency priorities change as different areas and regions experience other conflicts and disasters. However, those who remain unwilling or unable to return home for a number of reasons - including fear, lack of housing, jobs, education, or psychological trauma remain vulnerable. What this calls into question is how to determine who these very vulnerable people are, especially some length of time after the cessation of conflict.

The UNDP (10) has defined human security through seven separate, but related, indicators (Table 2). Though the use of these indicators is not unproblematic - for example, education is deemed a basic human right but is difficult to slot neatly into any particular indicator - they are open to interpretation. They are useful markers to identify those who are, or will, become vulnerable, and act as bench marks through which to gauge the successes and failures of policies and practices toward those perceived to be vulnerable. Precisely because these categories are broad, they are useful to demonstrate the wider, longer-term consequences of displacement.

\section{Table 2. UNDP Human Security Indications.}

\begin{tabular}{|ll|}
\hline 1. & Economic Security \\
2. & Food Security \\
3. & Health Security \\
4. & Environment Security \\
5. & Personal Security \\
6. & Community Security \\
7. & Political Security \\
Source: UNDP 1994
\end{tabular}

\section{Economic Security (assured basic income)}

In the long term, conflicts and displacement have a cumulative effect on the economy of a country, which in turn impacts on individual economic security. Conflict-related displacement causes wide scale demographic changes; there is often an increase in the number of female-headed households and subsequent gender imbalance due to the number of men killed in the fighting or leaving to seek work elsewhere. Migration to urban areas is common as agricultural-based economies disintegrate and enormous population movements during, and after, conflict may lead to an inexorable decline in industry. For many - particularly the younger members of the community - displacement may mean the opportunity to experience urban life for the first time, or to immigrate.

Many welfare areas, particularly education, healthcare, housing and employment, become fervently contested issues especially when combined with economic problems as different ethnic and/or religious groups, urban and rural residents, and domicile and displaced populations all compete to protect their own self interests. Along with oftenprecarious economic situations come high unemployment rates, particularly amongst refugee and IDP communities. In many parts of the world, women face discrimination in the workforce, they are often left out of employment training schemes, or are trained in semi-skilled occupations such as knitting and sewing. This raises questions about increasing opportunities and the means to empower local communities.

As many IDPs are reliant on state benefits and pensions - for example the elderly, widowed women, and the unemployed - the provision of social welfare can be problematic to already financially overstretched governments, especially those undergoing transition from one economic system to another (as in the former socialist countries). As programmes and funding sources dwindle, financial liability may increasingly shift to the IDPs themselves. For many families, financial assistance or pension entitlements are barely adequate to cover basic daily living expenses. Moreover, many are unaware of many of their rights and entitlements.

Economic security may ultimately underpin many other aspects of security. In fact, each of these domains is in someway reliant on the other: without food, people do not have the strength to work; without work, they may not have the money to buy food. IDPs and refugees are particularly vulnerable to economic hardships, and it is often economic deprivation that drove people to seek asylum or refuge in host countries in the first place. 


\section{Food Security (physical and economic access to food)}

The initial emergency phase of displacement may necessitate therapeutic or supplementary feeding programmes and the humanitarian provision of food supplies. However, as emphasis shifts toward more long-term planning, food supplies are often reduced or stopped altogether.

Food needs eventually become more focused on cost, availability and access. This includes safe access to potentially mined agricultural areas in order to grow crops, and the necessary tools and seeds. It is also contingent on actually having any land to farm, being in one place long enough to grow crops, being safe enough to work the land (for example, lone farmers and shepherds are often targeted by snipers in the disputed mountainous regions of Azerbaijan), and actually having the strength to do manual labour. It is important to remember that families may well rely on children to undertake these potentially dangerous tasks.

Another often-unforeseen problem is the lack of adequate nutrition and dietary advice, especially for the elderly. Many suffer from common, but problematic, complaints such as anaemia or diabetes, which without proper health education and advice may become more acute and life-threatening. However, given the limited finances and land available for IDPs in many parts of the world, in the long-term, poor diet and nutrition will continue to be a problem.

\section{Health Security (relative freedom from disease and infection)}

Health security is vital to ensure people can participate fully in their communities, seek education and employment, and generally have a better quality of life. As refugees fall under the care and protection of host countries, this section will focus on the problems encountered by IDPs, who are ostensibly the responsibility of their own government. Accessing healthcare provision should, therefore, be relatively simple. However, there are a number of factors to take into consideration.

Firstly, there are issues about availability of resources and proximity of healthcare centres. In many post-conflict (or postdisaster) situations, the provision of healthcare is inconsistent, particularly outside main urban areas, and may well have been so prior to the conflict/disaster. While money may well be available for reconstruction of decimated structures, it may not be enough to pay for staff salaries, consumables or equipment. In semipermanent resettlement camps in Azerbaijan, healthcare centres are built to a high standard and are staffed by competent healthcare workers, but have no drugs or equipment, therefore patients may be seen by a doctor, but have to buy their own drugs. This may necessitate a long journey by foot, public transport for those that can afford it, or if lucky, with a kindly relative or friend, to the nearest town as camps are often located some distance from main urban centres. This is especially problematic for those most likely to need repeated prescriptions - the elderly and infirm. This may lead to them having to make the decision to go without vital (but expensive) medications.

In many respects, those that have a long walk are the lucky ones. Many IDPs have almost no access to any form of medical care. The Global IDP Project reports that only 22 per cent of IDPs in Colombia receive medical attention, despite national legislation that entitles those who have registered to free and unlimited access to health care and medicines. However, many IDPs are afraid to officially register themselves for fear of reprisals, and many lack the requisite identity papers. In addition, many people report that hospitals commonly refuse to treat IDPs because the government often does not reimburse them the cost of the services provided. The Global IDP Project notes that as a result of this, over half of those displaced do not seek medical attention if they need it due to lack of money, and a recent survey puts morbidity among IDPs at six times the national average in Colombia(1).

The issue of registration often inhibits access to medical care; in the author's experience, the often complicated registration processes which ostensibly account for numbers and are used as the basis to provide aid can also restrict freedom of movement. For example, as part of the Peace Agreement, Bosnia and Herzegovina $(\mathrm{BiH})$ was divided along 'ethnic' lines into two entities. There now exists a complicated dual entity health insurance scheme, which means that people are only entitled to subsidised healthcare in the entity they are registered in. This is especially problematic for IDPs, who may be registered as living in one entity, but who for a number of reasons seek treatment in the other. One of the main reasons for this is the fear and reluctance to be treated by a doctor of the 'opposing' ethnicity, given the alleged complicity of many medical professionals during the conflict. It is inevitable given these constraints that IDPs feel discriminated against by their own medical services.

The often unsanitary and overcrowded living conditions in most refugee and IDP camps means that disease and illnesses are rife, and problems such as high blood pressure, asthma and other stress-related illnesses are exacerbated. The elderly, disabled, and children may be particularly vulnerable to long-term health problems. Women especially bear the brunt of conflict 
and displacement: many are widowed, have young families to care for, or be left as head of an extended household. Some women simply have no idea where their husbands or loved ones are - they are officially 'missing'. This not only has implications for the mourning process and their subsequent mental and physical health, but more pragmatically, for pensions and benefits, property claims and remarriage.

Although proportionally there are more female IDPs than male, very few governments have comprehensive policies to address their specific gender and reproductive health needs. A recent report found that although nearly a third of the displaced women in Columbia had had either miscarriages or stillbirths, only 63 per cent had received any form of treatment or medical intervention (1). Women may have experienced ethnic cleansing, genocide, rape, or sexual violence before, during and after conflict and displacement. In many instances, gender-based violence is often ignored, and many of the health problems suffered by women remain undetected in part due to the shame associated with them. Few of the women (or men) who testify at international war crimes tribunals and courts are offered any kind of witness protection plan, and often have to return to the very communities where their perpetrators still live.

The effect of conflict and long-term displacement on children is hard to calculate, but undoubtedly growing up in camps raises questions about their futures. There is often a great deal of responsibility placed on younger children (especially sons) to provide and care for their families. Despite this, education is often deemed a priority, as it offers a means to better oneself, find employment and seek opportunities to work abroad. This in turn raises questions about 'brain drain' and the ability of communities to sustain such outmigration. Barriers to education again include financial wherewithal and physical access, lack of teachers, school buildings, and discriminatory curriculums.

There is an ongoing debate about the implementation of psychosocial programmes that could address many of the concerns raised here. Somatisation of psychological distress may cause confusion and difficulty in diagnosing and managing physical symptoms. Overall, for specialist agencies in the field, the best response to managing the psychological sequelae of conflict/displacement has been twofold: initially to 'normalise' responses - reassuring people that what they are feeling is a natural response to a series of terrible and traumatic events, suggesting simple coping strategies to enable them to carry on in the short term, and identifying the minority of those with severe, disabling mental health problems that require specialist help. Nevertheless, as
Summerfield (8) has pointed out, these specifically targeted psychosocial programmes that confront issues of fear, grief and trauma should be carried out within the context of the local community, rather than drawing attention to issues which only serve to marginalise people further from their own communities. The debate about medicalising stress and trauma is ongoing, but raises a point that the interesting categorisation of trauma and post traumatic stress disorder (PTSD) may ultimately prove to be detrimental to the people they purport to assist. Denying these as categories of psychiatric diagnosis may also invalidate them as reasons to provide support and asylum.

\section{Environmental Security (access to sanitary water supply, clean air and a non-degraded land system)}

For both refugees and IDPs, accommodation in the early stages is more often than not in makeshift tented camps. Depending on the duration of displacement, semi-permanent collective centres or settlements may be constructed by NGOs using donor funds. However, for all those living in tents, collective centres and camps, their situation is precarious and temporary, and subject to many to variables - including weather, accessibility, and availability of utilities and transport. Moreover, a large proportion of refugees and IDPs do not even end up in semi-organised settlements, but stay with friends, relatives or even private accommodation. These people have effectively fallen through the already very loose net, and are even more vulnerable.

Issues of property and housing are paramount to IDPs - many have lost their homes after fleeing conflict or violence. As was the case in $\mathrm{BiH}$, wide scale destruction of properties led to a depletion of housing stock across the country, leaving people displaced and homeless for extended periods of time. Legislation for compensation and reconstruction was often complicated, with many clauses. Little account was taken of the actual process of rebuilding, the need for manpower, the freezing Bosnian winters, the remoteness of many of the return villages and lack of utilities. There was also the issue of illegal occupation - part of the process of ethnic cleansing involved moving families into empty properties as families fled disputed areas. This has led to the situation in $\mathrm{BiH}$ whereby IDPs remain effectively 'homeless' if another family is illegally occupying their house. However, if their house is also being illegally occupied, it is easy to see how these become protracted disputes.

The threat of the explosive remnants of war (ERW) - land mines, cluster bombs, and 
unexploded ordinance (UXO) - severely compromises environmental security and puts displaced populations, and those returning to their homes, in an especially vulnerable position. ERW cause devastating injuries and loss of life and limb, often in areas where hospital access, treatment and rehabilitation are poor (see section 3 above). Sequelae to this include loss of livelihood, discrimination, depression, and poor marriage prospects. ERW impede return processes, agricultural work, and thus compromise economic and food security. Clearance is a slow and specialised business, which, given the heavy and indiscriminate mining of many post-conflict areas, will take many years to complete. The presence of ERW poses a substantial threat to the regeneration of post-conflict/disaster affected areas, and a considerable challenge to efforts of peace and reconciliation.

\section{Personal Security (security from physical violence and threats)}

IDPs and refugees are particularly vulnerable to threats and intimidation from opposing political or ethnic groups who may well have been the cause of their initial displacement, as is the case for example in the Darfur region of Sudan and for the Kurds in Iraq. The IDP crisis in Colombia has become one of the world's worst in its protracted 40-year struggle between the Colombian Revolutionary Armed Forces (FARC) and the National Liberation Army (ELN). Though this was initially an armed struggle for land and social equality, it has led to the displacement of millions of the country's most vulnerable and economically impoverished groups: the Afro-Colombians and indigenous peoples. They have been deliberately displaced as part of strategies to take over territories, land (to cultivate narcotics) and properties. They face continued attacks and reprisals, and are often accused of supporting the 'wrong' side. In 2003, an estimated 30,000 people were displaced due to a government policy to fumigate illicit crops to deprive the armed groups of a major source of income. However, this not only destroyed the illicit narcotics but also the staple food crops and devastated the livelihood of Colombian peasants (1).

Women and children in particular face harassment and danger in camps and centres, and not only from opposition groups. As noted above, rape and genderbased violence are endemic both as a cause and result of displacement, even in the refugee and IDP camps. In Uganda, IDP camps were the targets of attacks and there were numerous reports of widespread sexual abuse of women and children (1). Research had demonstrated that following conflict, incidents of domestic violence increase as a result of a combination of factors, such as ensuing post-traumatic stress, loss of livelihood and depression (10).

Security and safety issues are paramount to displacement and return. In $\mathrm{BiH}$, many donors assumed that people would be happy to return to towns and villages once their houses were reconstructed, despite the fact they may have experienced atrocities at the hands of their 'friends' and neighbours. There have been countless reports of returnrelated violence, which only fuel further anxieties. Inevitably, IDPs and refugees are very susceptible to fear, and psychological security is as important to maintain as physical security for personal security. Moreover, allaying fears about security may actually promote return in certain circumstances.

\section{Community Security (security of cultural identity)}

Many conflicts have resulted in atrocities being committed by those who had previously been close friends and neighbours - as was particularly striking in Bosnia and Rwanda. This inevitably destroys any sense of community. Moreover, loss of one's homeland may lead to a loss of cultural identity as cultural and ethnic groups are dispersed and segregated following displacement. The security, dignity and freedom to practise cultural and religious beliefs is an essential part of preserving a sense of identity, though this may not be at all possible in circumstances of displacement. Conversely, a sense of cultural identity may be strengthened in exile.

Community leaders, religious leaders and women may be well placed to maintain community identity and keep cultural practices and traditions. However, perpetuating ethno-religious differences gives credence to often-disputed issues of justice, war crimes and genocide. Merely implementing Rule of Law, or invoking the international community, does not promote reconciliation amongst different communities, and continuing resentments are an impending disaster in terms of future peace.

Problems may well continue if, and when, the displaced return home. What or where 'home' is may only exist in the memories of refugees and IDPs. Many factors tie people to their homeland, including language, religion and sacred places. Many elderly refugees and IDPs wish to return home to ensure they will be buried with their ancestors. Returning home may not meet everyone's expectations; many do not realise that home will inevitably have undergone a great deal of change in the intervening time. There may be jealousy, survivors guilt, adjustment difficulties, loss of benefits and subsidies, and the practicalities of finding 
work, schooling, and a social support network. This is especially important, as even though houses may be rebuilt, without people, networks, and social structures a community cannot function.

\section{Political security (protection of basic human rights and freedoms)}

IDPs have the right to be treated with the same respect and dignities afforded to all citizens of their country; however the political circumstances surrounding displacement often impede this. Despite their duty to protect citizens, a number of countries have been accused of deliberately using their own government forces, militias or insurgent groups to target civilian groups and forcibly expel them from their homes. As the Global IDP report notes, such wanton acts of violence as murder, torture, rape, forced recruitment and labour, looting and destruction of properties, constitute serious human rights violations and breaches of international law. However, there has been little recourse as yet for many of those who have suffered as a result of this.

The three resolutions to displacement return, repatriation or, resettlement (including asylum in another country) - are obviously not unproblematic and again call into question issues of human rights and freedom of movement. The end of internal displacement should be a voluntary decision, depending on legislation, political, economic and social reforms, and the successful transition to peace or a return to 'normalcy'. IDPs should not feel forced to return or to remain; however, the very issues that influence the decision to return are often the very same as those that influence the decision to remain. These push/pull factors include security, equality, employment, land, and access to education, healthcare, and housing.

As the return process is usually the responsibility of the host country it can be difficult to monitor and assess. In $\mathrm{BiH}$, partly as a result of issues of responsibility and funding, many humanitarian aid programmes ceased once the beneficiaries returned home, thus reinforcing the social welfare responsibilities of the state. The issue of responsibility can only be massively compromised if it was the state that caused (however indirectly) the displacement in the first place, leaving IDPs in a very precarious and vulnerable situation. Either way, those remaining in camps may be left with little or no social welfare, and little or no hope for the future, and those returning home may face fear, discrimination, unemployment and a whole host of other problems.

The protracted nature of many situations of displacement highlights the need to continue with efforts to assist IDPs out of the poverty, discrimination, property disputes, unemployment and the legal situations that burden them. One of the lessons to be learned from the protracted IDP situations in $\mathrm{BiH}$ and elsewhere in the world is that many displaced people do eventually return home, albeit after a considerable length of time. By the end of 2003, the Global IDP report notes, any of the threats and violence that caused the displacements in the first place were no longer the major obstacles; these were now political inertia and lack of economic resources.

\section{Conclusions and Implications}

IDPs face fear and discrimination in many aspects of daily life - from accessing healthcare, education and employment, to the loss of land and traditional livelihood skills, and disintegration of family and community structures. They face a loss of independence, and may even face obstruction or persecution by the very state that is supposed to protect them. Therefore, as these human security indicators have demonstrated, IDPs (and refugees) are vulnerable to a number of insecurities that extend beyond the physical, and these have far-reaching implications.

Inevitably they impact on one another: health security enables people to function in their daily lives as without good health they may not be able to work. Conversely, without economic security, for example, they may not have the money necessary to travel to places of employment. These overlapping and interlinking aspects of human security result in IDPs being especially vulnerable to the vicissitudes of state and international policies, yet are reliant on them for humanitarian assistance, welfare, and even food and shelter.

In summary, it has been the aim of this article to demonstrate to healthcare professionals the wider social, political and cultural contexts that can be both the causes and effects of displacement and the range of factors that can increase the vulnerability of affected populations. These broader consequences have been demonstrated through the UNDP human security indicators, and how conflict, disaster, trauma and displacement can compromise them. Being mindful of these wider contexts will assist healthcare professionals in their understanding of refugee and IDP situations both at home and abroad, and demonstrate once again that the scope of medical care extends far beyond the hospital setting.

\section{References}

1. Global IDP Project 2004. URL: www.idpproject.org/global_overview.html.

2. Schmeidl S. 2003 The early warning of forced migration: State or human security? In Newman E. and van Selm, J. eds. Refugees and Forced Displacement: International Security, Human Vulnerability, and the State. Tokyo and New York: United Nations University Press. 
3. Mooney ED. 2003. Towards a protection regime for internally displaced persons.' In Newman E. and van Selm, J. eds. Refugees and Forced Displacement: International Security, Human Vulnerability, and the State. Tokyo and New York: United Nations University Press.

4. Tempest $M$ and agencies. Iraq may fail as a state. The Guardian Thursday July 29 2004. URL: http://politics.guardian.co.uk/iraq/story/0,12956,12 71728,00.html.

5. Médecins Sans Frontieres 1997. Refugee Health: An Approach to Emergency Situations. London and Oxford: Macmillan.

6. Newman E. and van Selm, J. eds. Refugees and Forced Displacement: International Security, Human Vulnerability, and the State. Tokyo and New York: United Nations University Press.

7. Ager A. 1999. Perspectives on the refugee experience. In Ager A.ed. Refugees: Perspectives on the Experience of Forced Migration. Pinter: London and New York.

8. Summerfield D. 1999. Sociocultural dimensions of war, conflict and displacement. In Ager A.ed. Refugees: Perspectives on the Experience of Forced Migration. Pinter: London and New York.

9. Harrel-Bond B.1999 The experiences of refugees as recipients of aid. In Ager A.ed. Refugees: Perspectives on the Experience of Forced Migration. Pinter: London and New York.

10. United Nations Development Programme 1994. New Dimensions of Human Security. Human Development Report

11. Colson E. 2003. Forced Migration and the Anthropological Response fournal of Refugee Studies 16 (1).

$c$ 